Article

\title{
Isolation and Characterization of a Marine Microalga for Biofuel Production with Astaxanthin as a Co-Product
}

\author{
Zhiyong Liu ${ }^{1,2}$, Chenfeng Liu ${ }^{1,2}$, Yuyong Hou ${ }^{2}$, Shulin Chen ${ }^{2}$, Dongguang Xiao ${ }^{1}$, \\ Juankun Zhang ${ }^{1}$ and Fangjian Chen ${ }^{2, *}$
}

1 College of Biotechnology, Tianjin University of Science and Technology, Tianjin 300457, China; E-Mails: zhiyong618@yahoo.cn (Z.L.); liuchenfeng0304@sina.com (C.L.); xiao99@tust.edu.cn (D.X.); zhangjk@tust.edu.cn (J.Z.)

2 Tianjin Key Laboratory for Industrial Biological Systems and Bioprocess Engineering, Tianjin Institute of Industrial Biotechnology, Chinese Academy of Sciences, Tianjin 300308, China; E-Mails: hblghyy@163.com (Y.H.); chen_sl@tib.cas.cn (S.C.)

* Author to whom correspondence should be addressed; E-Mail: chen_fj@tib.cas.cn; Tel./Fax: +86-22-84861993.

Received: 6 February 2013; in revised form: 17 May 2013 / Accepted: 18 May 2013 / Published: 29 May 2013

\begin{abstract}
Microalgae have been considered as a promising biomass for biofuel production, but freshwater resource consumption during the scaled-up cultivation are still a challenge. Obtaining robust marine strains capable of producing triacylglycerols and high value-added metabolites are critical for overcoming the limitations of water resources and economical feasibility. In this study, a marine microalga with lipid and astaxanthin accumulation capability was isolated from Bohai Bay, China. The alga was named as Coelastrum sp. HA-1 based on its morphological and molecular identification. The major characteristics of HA-1 and the effects of nitrogen on its lipid and astaxanthin accumulations were investigated. Results indicated that the highest biomass, lipid and astaxanthin yields achieved were $50.9 \mathrm{~g} \mathrm{~m}^{-2}$ day $^{-1}, 18.0 \mathrm{~g} \mathrm{~m}^{-2}$ day $^{-1}$ and $168.9 \mathrm{mg} \mathrm{m}^{-2}$ day $^{-1}$, respectively, after cultivation for 24 days. The fatty acids of HA-1, identified in their majority as oleic acid (56.6\%) and palmitic acid (25.9\%), are desirable biofuel feedstocks. In addition, this alga can be harvested with simple sedimentation, achieving $98.2 \%$ removal efficiency after settling for $24 \mathrm{~h}$. These results suggest that Coelastrum sp. HA-1 has several desirable key features that make it a potential candidate for biofuel production.
\end{abstract}


Keywords: astaxanthin; biofuel; Coelastrum sp. HA-1; marine microalgae; microalgae removal efficiency

\section{Introduction}

With the dwindling reserves of fossil fuels and the need to reduce greenhouse gas emissions, biofuels are considered to be an attractive source of energy [1]. Among the various feedstocks for biofuel production, microalgae have received great attention in recent years owing to their potential high productivities, high contents of triacylglycerols and flexibility for cultivation on non-arable land. However, some major technical challenges have to be addressed before algal biofuel becomes a commercial reality [2]. For instance, major technical barriers remain in the availability of novel algae strains, high lipid productivity, and low harvesting cost [3]. Additionally, commercialization of algal biofuels is also subject to limitations of water resources and economics. As there are conflicting uses of available freshwater, whereas seawater is abundant, it is more advantageous to use microalgae adapted to seawater for biofuel production. None of the research and development efforts to date have been able to demonstrate economical production of biofuel from microalgae. Thus, strains with valuable co-products offer an avenue for cost reduction [4]. Many bioactive compounds have been reported as having potential to be valuable co-products, such as pigments, antioxidants, eicosapentanoic acid, docosahexaenoic acid, and biofertilisers [5]. Among them, astaxanthin is a powerful, high-value, biological antioxidant. Astaxanthin production with microalgae has achieved considerable commercial success [6]. In addition, harvesting microalgae is another major difficulty in large-scale production of microalgae-derived biofuels because of their small cell size and low concentration in cultures [4]. It was estimated that the cost of harvesting algal biomass accounts for $20 \%-30 \%$ of the total production costs [7]. Therefore, a strain with the features of having high biomass productivity, high lipid content, valuable co-products, efficient-harvesting possibility, and using seawater is highly desirable to make biofuel produced from microalgae feasible.

Another strategy for more economical algae culture is enhancing the production of most desirable products. In different microalgal species, the proportions of lipids, proteins, carbohydrates and pigments are different. It was reported that microalgal metabolism is influenced by some environmental factors such as temperature, illumination, $\mathrm{pH}$, salinity and most markedly, nutrient availability [8]. Improvement of a certain product like lipid or pigment can be achieved by optimization of these factors.

For the purpose of searching for the most desirable algal strain, 56 marine microalgae from Bohai Bay, China, were isolated. One of them, HA-1 had a high biomass productivity. In addition, the color of HA-1 became orange-red gradually during cultivation, which was similar to the astaxanthin accumulation stage of the commercial freshwater microalga Haematococcus pluvialis [9]. Hence, the aim of this study was to investigate the characteristics of HA-1 in terms of strain identification, astaxanthin and lipid accumulation, and harvesting. 


\section{Experimental Section}

\subsection{Strains and Culture Conditions}

The main algal strain used in this study was HA-1 isolated from a seawater sample collected from Dongjiang Port, Tianjin, China $\left(117.82^{\circ} \mathrm{E}, 39.01^{\circ} \mathrm{N}\right)$. Two other microalgae strains, Chlorella sorokiniana (UTEX 1602) from the Culture Collection of Alga at the University of Texas (Austin, TX, USA) and Nannochloropsis oculata (CCAP 849/1) from the Culture Collection of Algae and Protozoa at Scottish Marine Institute (Oban, Argyll, UK), were also used in cell settling tests.

The marine algae HA-1 and $N$. oculata were grown in filtered seawater complemented with F medium [10]. C. sorokiniana was cultivated using Bold's Basal Medium [11]. Temperature and $\mathrm{pH}$ were $25 \pm 1{ }^{\circ} \mathrm{C}$ and $7.5 \pm 0.2$, respectively. All primary stock cultures were maintained aerobically in $250 \mathrm{~mL}$ Erlenmeyer flasks under continuous artificial illumination at $100 \pm 10 \mu \mathrm{mol} \mathrm{m} \mathrm{s}^{-2}$. The algae cultured in columns were aerated with air enriched with $2 \%(v / v) \mathrm{CO}_{2}$ under continuous artificial illumination at $150 \pm 10 \mu \mathrm{mol} \mathrm{m} \mathrm{s}^{-2}$.

\subsection{Electron Microscopy Morphology Analysis}

To observe the cell morphology and structure, scanning electron microscopy (SEM) and transmission electron microscopy (TEM) studies were carried out. For SEM, $5 \mathrm{~mL}$ cultures were harvested and fixed with glutaric dialdehyde for $24 \mathrm{~h}$. Then the cells were embedded using the glutaraldehyde, tannic acid, guanidine hydrochloride, osmium tetroxide (GTGO) technique [12], coated with gold, and examined under the SEM microscope (Quanta200; FEI, Hillsboro, OR, USA). For the TEM analysis, the harvested cells were fixed with $1 \%$ glutaric dialdehyde for $24 \mathrm{~h}$, separated by centrifugation for $5 \mathrm{~min}$ at $1000 \times \mathrm{g}$, then washed five times with $0.1 \mathrm{M}$ phosphate buffer. The processed materials were fixed with $1 \%$ osmic acid for $6 \mathrm{~h}$ and then washed three times with $0.1 \mathrm{M}$ phosphate buffer. The cells were dehydrated with increasing concentrations of ethanol up to $100 \%$ and anhydrous acetone. The cell samples were then soaked in an anhydrous acetone/Epon812 resin (7:3) mixture for $5 \mathrm{~h}$, followed by an epoxy propane/Epon812 resin (3:7) mixture for $6 \mathrm{~h}$, then Epon812 for $5 \mathrm{~h}$, after which they were finally embedded in Epon812 resin. Photographs were taken under the TEM microscope (JEM-1400; JEDL, Tokyo, Japan).

\subsection{Phylogenetic Analysis}

In order to further identify the strain species, the genomic DNA was extracted based on the method of Fast-Prep DNA purification [13]. Two universal green algal primers, 18SF (forward, 5'-CCTGGTTGATCCTGCCAG-3') and 18SR (reverse, 5'-TTGATCCTTCTGCAGGTTCA-3'), were used for PCR amplification of the $18 \mathrm{~S}$ rDNA. The PCR reaction was performed with a thermal program, which consisted of preheating at $94{ }^{\circ} \mathrm{C}$ for $5 \mathrm{~min}, 30$ cycles of denaturation at $94{ }^{\circ} \mathrm{C}$ for $1 \mathrm{~min}$, annealing at $55{ }^{\circ} \mathrm{C}$ for $1 \mathrm{~min}$, and extension at $72{ }^{\circ} \mathrm{C}$ for $2 \mathrm{~min}$, there was a final $5 \mathrm{~min}$ extension period at $72{ }^{\circ} \mathrm{C}$ prior to a $4{ }^{\circ} \mathrm{C}$ hold.

Phylogenetic analysis was performed using MEGA5 for Windows [14]. The phylogenetic tree was constructed using the Neighbor-Joining method [15]. The percentage of replicate trees in which the 
associated taxa clustered together in the bootstrap test (1000 replicates) greater than $50 \%$ were shown next to the branches [16]. The tree was drawn to scale, with branch lengths in the same units as those of the evolutionary distances. These distances were computed using the Maximum Composite Likelihood method and in the units of the number of base substitutions per site [17].

\subsection{Lipid Extraction and Fatty Acid Analysis}

After culturing 24 days, cells were harvested with centrifugation at $7000 \times g$ for $10 \mathrm{~min}$. The pelleted cells were lyophilized using a freeze drier (Alpha 2-4/LSC; Martin Christ GmBH, Osterode, Germany). The total lipids were extracted from dry mass according to Yuan et al. [18]. All lipids extracted were dissolved in $1 \mathrm{~mL}$ chloroform and $2.5 \mathrm{~mL} 2 \%(v / v) \mathrm{H}_{2} \mathrm{SO}_{4}$-methanol solution, and then heated at $85{ }^{\circ} \mathrm{C}$ for $2.5 \mathrm{~h}$ in a water bath. $1 \mathrm{~mL}$-hexane and $1 \mathrm{~mL}$ saturated sodium chloride were added, and fatty acid methyl ester (FAME) was dissolved in the upper layer.

Analysis of the FAME was carried out using GC-MS (7890A-5975C, Agilent Technologies Inc., Wilmington, DE, USA) with an Agilent HP-5 column (5\% phenylmethylsiloxane, $30 \mathrm{~m} \times 0.25 \mathrm{~mm} \times$ $0.25 \mu \mathrm{m})$ as described by Yang et al. [19]. The identification of fatty acid (FA) was accomplished by comparing the mass spectra to the National Institute of Standards and Technology (NIST) mass spectral library (NIST08.L).

\subsection{Pigment Extraction and Analysis}

Extraction of pigment was carried out in a Soxhlet apparatus. Dry algae biomass ( $0.5 \mathrm{~g})$ was mixed with pure acetone $(250 \mathrm{~mL})$ using the Soxhlet apparatus method [9]. The extracts were analyzed using a HPLC (Shimadzu Co., Kyoto, Japan) equipped with a diode array detector using a Hypersil C18 column $(5 \mu \mathrm{m}, 250 \mathrm{~mm} \times 4.6 \mathrm{~mm})$. The mobile phase was $90 \%$ carbinol at a flow rate of $1 \mathrm{~mL} / \mathrm{min}$. The oven temperature was $30^{\circ} \mathrm{C}$. The injection volume was $10 \mu \mathrm{L}$. Samples were detected at $450 \mathrm{~nm}$ with astaxanthin standard (Sigma, St. Louis, MO, USA) as control. Individual carotenoids could be identified by their typical retention times compared to standard samples of pure carotenoid.

\subsection{Cell Settling Tests}

To characterize the sedimentation property of HA-1, settling test was carried out, with $N$. oculata and $C$. sorokiniana designed as control. Microalgae were settled in tubes for $30 \mathrm{~h}$ when cultures were about $1 \mathrm{~g} / \mathrm{L}$. The removal efficiency of algal was measured by $\mathrm{OD}_{680}$ at different time $(t)$ during the settling process. Samples were taken at $5 \mathrm{~cm}$ below the culture surface in the container. The removal efficiency was calculated using Equation (1) according to Chen et al. [7].

$$
\text { Removal efficiency }(\%)=\left(1-\frac{\mathrm{OD}_{\mathrm{t}}}{\mathrm{OD}_{0}}\right) \times 100 \%
$$

where $\mathrm{OD}_{0}$ is the initial optical density of the culture for the settling process; and $\mathrm{OD}_{t}$ is the optical density of the culture at time $t$. Experiments were performed in triplicates, and data are shown as mean and standard error of the mean. 


\subsection{Effects of Initial $\mathrm{NaNO}_{3}$ Concentration on Microalgae Growth, Lipid and Astaxanthin Accumulation}

In order to estimate the growth of microalgae, the dry cell weight (DCW) was measured according to Couso et al. [20]. Microalgae were cultured to the log phase of growth in flasks, then $50 \mathrm{~mL}$ cell cultures were transferred to glass columns $(4.1 \mathrm{~cm}$ in diameter, $37 \mathrm{~cm}$ in height), and diluted with $250 \mathrm{~mL}$ of $\mathrm{F}$ medium with different concentrations of $\mathrm{NaNO}_{3}(0.075,0.15,0.3,0.6$ and $0.9 \mathrm{~g} / \mathrm{L})$ to ensure the $\mathrm{OD}_{680}$ of initial culture was approximate 0.2 . The nitrogen concentration during growth was monitored according to Yuan et al. [18]. Lipid and astaxanthin accumulations were analyzed according to the method mentioned above.

\section{Results and Discussion}

\subsection{Molecular Identification}

There were 1733 nucleotides in the $18 \mathrm{~S}$ rDNA gene sequences obtained from marine microalgae HA-1. This sequence was assigned an accession number of JX413790 after submitting to the National Center for Biotechnology Information (NCBI). Nucleotide sequences of other 12 species were obtained from the NCBI database based on the BLAST results of JX413790 in the 18S rDNA gene analyses. The amplified 18S rDNA gene sequence was found to have $>99 \%$ identity with that of previously sequenced Coelastrum sp. strains in the NCBI database. Based on the 18S rDNA gene phylogenetic analysis, HA-1 was found to be close with Coelastrum proboscideum var. gracile strain SAG 217-3 (GQ375099.1) (Figure 1), and named Coelastrum sp. HA-1.

Figure 1. Dendrogram inferred from $18 \mathrm{~S}$ rDNA gene sequences of strain HA-1. Neighbor-Joining method was used to construct the distances within the tree by MEGA5. The branch lengths are proportional to the evolutionary distances. Bootstrap values $(>50 \%)$ from the bootstrap test (1000 replicates) are shown next to the branches.

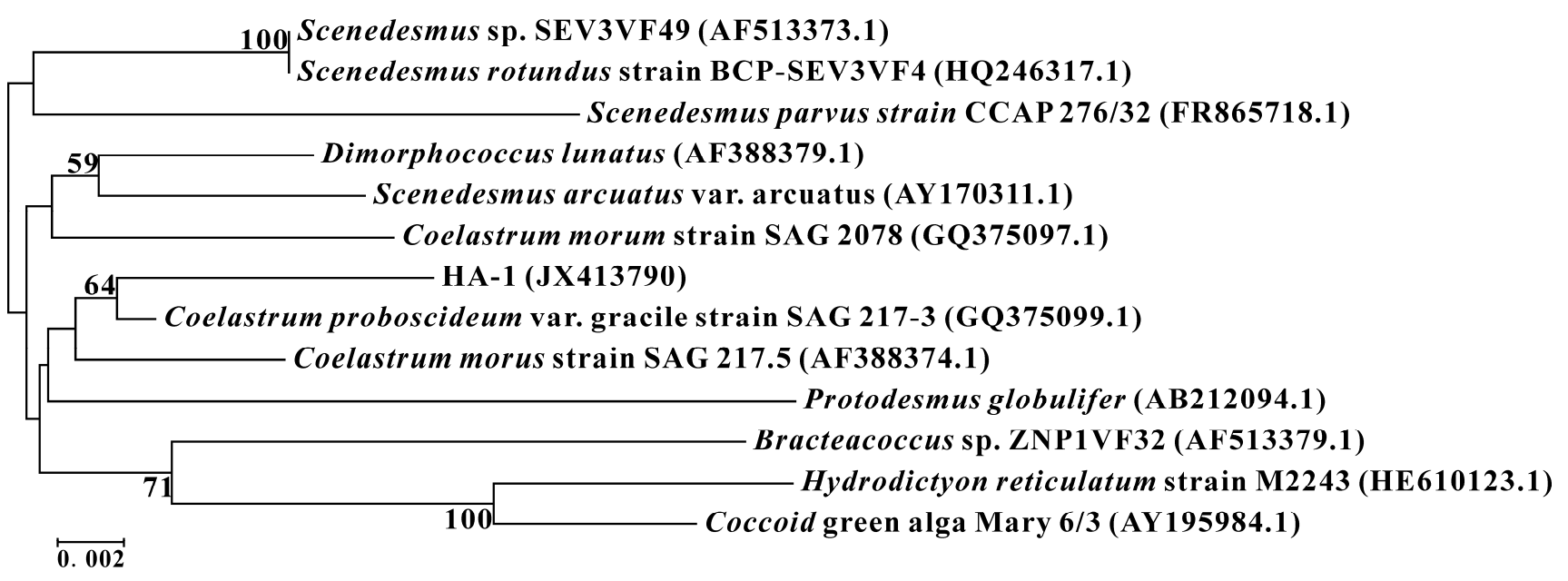

\subsection{Morphology Analysis}

The SEM analysis results showed that cells of Coelastrum sp. HA-1 were unicellular and spheroidal (Figure 2). The cell size varied from 8 to $12 \mu \mathrm{m}$ in diameter and cell wall consisted of a trilaminar sheath, which is similar with Coelastrum sphaericum in a previous work [21]. 
Figure 2. Microscopy and morphological appearance of strain HA-1. Scanning electron micrographs $(1000 \times)$ of cells in green stage (a) and red stage (b). Transmission electron micrographs $(4000 \times)$ of cells in green stage (c) and red stage (d). Chloroplast $(\mathrm{Ch})$ and Plastoglobule $(\mathrm{P})$ in red cells are shown.

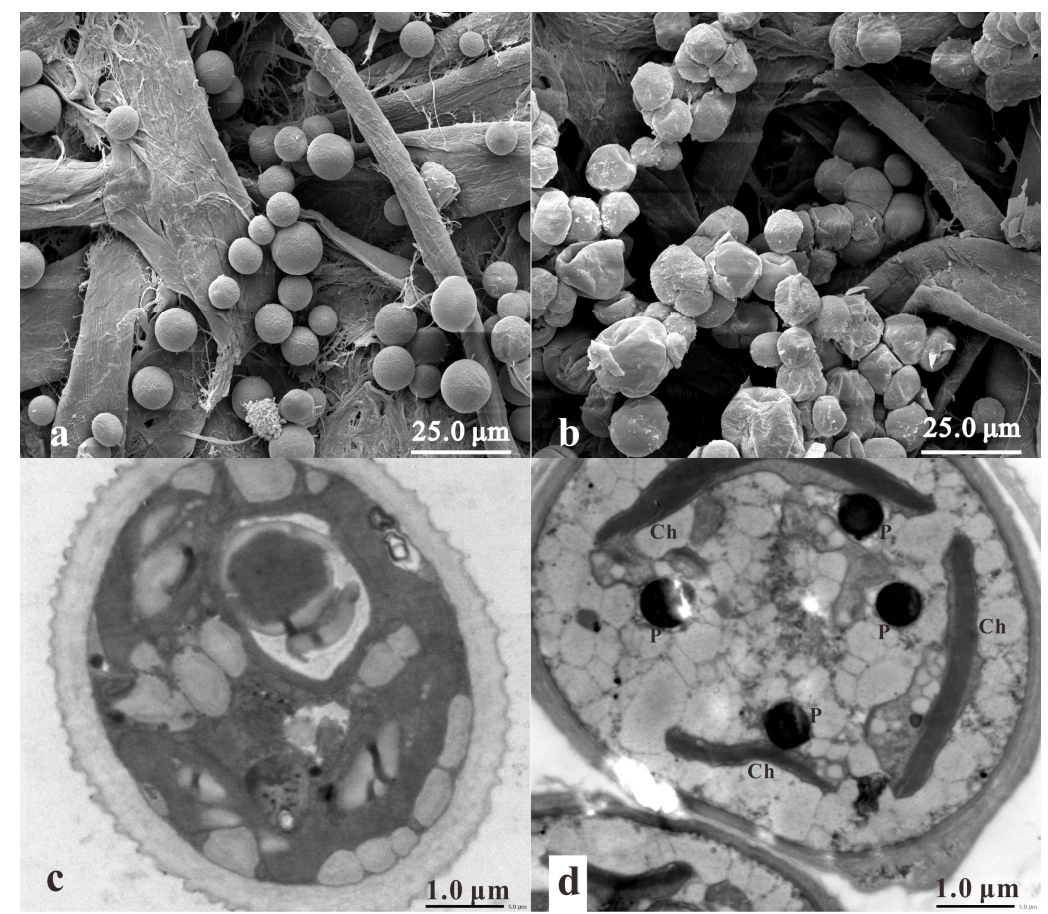

The color of the cells was green in the early stage of growth, and then it gradually changed to red. Coelastrum sp. HA-1 was spherical, and the cell wall was smooth in the green stage (Figure 2a), which is identical with the previous report for C. sphaericum [22], so the cellular morphology supported the molecular identification result. In the red stage, cells were wrinkled, and the cell wall was abridged (Figure 2b). It has been reported that the synthesis of carotenoids was subject to detrimental conditions, such as high light intensity, nutrient starvation or other stress conditions [20]. Thus, it was inferred that the red cell might have been under stress. Similar results reported by Gao et al. also showed that the surface of Haematococcus pluvialis cells changed drastically during astaxanthin accumulation [23]. The TEM analysis results indicated that several meniscoid shaped chloroplasts (Ch) and round plastoglobule (P) appeared in the red cells (Figure 2d). Thylakoid lamellae of chloroplasts were also distinct in these cells. Collins thought that astaxanthin was distributed within globular and punctate regions of the cytoplasmic space, and $\beta$-carotene, a precursor of astaxanthin, was co-located within both the chloroplast and astaxanthin in the cytosol [24], so the presence of chloroplasts and plastoglobule in the red cells might be evidence that astaxanthin accumulates in the cells of Coelastrum sp. HA-1.

\subsection{Identification and Quantification of Astaxanthin}

The extracts from Coelastrum sp. HA-1 had a peak at the same retention time as the astaxanthin standard (Figure 3), which confirmed the presence of astaxanthin in the cell. The concentration of astaxanthin was calculated according to the standard sample concentration and HPLC peak area, and the result showed that astaxanthin concentration was $16.4 \mathrm{mg} / \mathrm{L}$. Although the concentration of astaxanthin 
was higher than that found in Chlorella zofingiensis $(15 \mathrm{mg} / \mathrm{L})$ reported by Del Campo et al. [25] and H. pluvialis $(8.3-10.69 \mathrm{mg} / \mathrm{L})$ reported by Sarada et al. under $\mathrm{NaCl}$ stress [26], it was lower than Zhekisheva's report that astaxanthin increased from 36 to $58.5 \mathrm{mg} / \mathrm{L}$ in $H$. pluvialis under nitrogen-starved conditions [27]. Further research should be done to improve the astaxanthin content through stress caused by illumination, temperature, salinity and genetic modification of $\beta$-carotene ketolase and $\beta$-carotene hydroxylase. Commercial astaxanthin production from marine microalgae has not been reported. The discovery of astaxanthin in Coelastrum sp. HA-1 provides an alternative natural source of astaxanthin.

Figure 3. HPLC analysis of astaxanthin. Extracts from Coelastrum sp. HA-1 (b) had a peak at the same retention time as the astaxanthin standard (a).
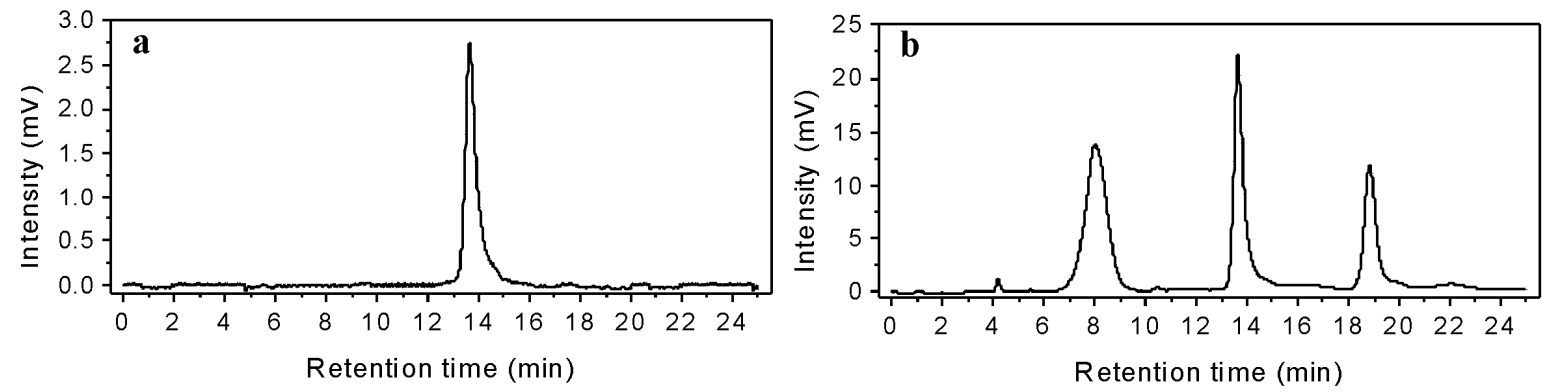

\subsection{Fatty Acid (FA) Composition}

The total lipid content of Coelastrum sp. HA-1 was about $43.2 \%$ of DCW (dry cell weight) after cultivation for 24 days in F medium, which was higher than that of $H$. pluvialis $(32.99 \%$ ) under continuous high light intensity and nitrogen-deprivation medium [28]. The 11 individual FAMEs were detected and identified as listed in Table 1.

Table 1. Fatty acid composition of Coelastrum sp. HA-1.

\begin{tabular}{ccc}
\hline Fatty acids & Relative content of the total fatty acids $(\%, \boldsymbol{w} / \boldsymbol{w})$ & More than half of the total fatty acids \\
\hline C14:0 & 0.28 & No \\
C16:0 & 25.86 & No \\
C16:1 & 5.46 & No \\
C16:2 & 4.23 & No \\
C16:4 & 1.24 & No \\
C18:0 & 3.36 & No \\
C18:1 & 56.63 & Yes \\
C18:2 & 0.99 & No \\
C18:4 & 0.57 & No \\
C20:1 & 0.75 & No \\
C28:0 & 0.63 & No \\
\hline SFA & 30.13 & No \\
UFA & 69.87 & Yes \\
MUFA & 62.84 & Yes \\
PUFA & 7.03 & No \\
\hline
\end{tabular}

Notes: SFA is saturated fatty acid; UFA is unsaturated fatty acid; MUFA is monounsaturated fatty acid; and PUFA is polyunsaturated fatty acid. 
Saturated fatty acid (SFA) and unsaturated fatty acid (UFA) were 30.13\% and $69.87 \%$ of total fatty acids, respectively. It was suggested that a high ratio of monounsaturated fatty acid (MUFA) to polyunsaturated fatty acid (PUFA) is desirable for biodiesel production and low concentrations of PUFA could contribute to satisfactory low temperature operability and oxidative stability [29]. Within UFA of HA-1, MUFA and PUFA were $62.84 \%$ and $7.03 \%$, respectively. Xu et al. reported that high-quality biodiesel was usually obtained from 18 carbon fatty acids, including oleic acid methyl ester and octadecenoic acid methyl ester [30]. The major FA of HA-1 was oleic acid (C18:1), which accounted for more than $50 \%$ of the total FAs. The second major FA was palmitic acid (C16:0), and hexadecenoic acid (C16:1) was the third, accounting for $25.9 \%$ and $5.5 \%$ of total fatty acids, respectively. The FA profile of HA-1 was suitable for biofuel.

\subsection{Removal Efficiency of HA-1}

The results show that the removal efficiency of Coelastrum sp. HA-1 by settling was $63.1 \%$ in one hour and $98.2 \%$ at $24 \mathrm{~h}$. In contrast, sedimentation efficiency of Nannochloropsis oculata and Chlorella sorokiniana only reached $6.1 \%$ and $9.1 \%$ at $24 \mathrm{~h}$, respectively (Figure 4 ) in this time. Harvesting microalgae is one of the major difficulties in the commercialization of microalgae-derived biofuels and the cost of harvesting is estimated as $20 \%-30 \%$ of the total production costs. Uduman et al. summarized the performances of different harvesting techniques, and gravity sedimentation was the process with the lowest cost [31]. On the other hand, efficient sedimentation might lead to higher energy consumption on suspending microalgae during the cultivation; however, the experiment results in this study showed that strain HA-1, N. oculata and $C$. sorokiniana all reached the optimum conditions using the same air flow rate $(100 \mathrm{~mL} / \mathrm{min})$ for aerating. Therefore, using sedimentation alone for harvesting Coelastrum sp. HA-1 would make it more economical for biofuel production.

Figure 4. Microalgae removal efficiency of Coelastrum sp. HA-1, Nannochloropsis oculata and Chlorella sorokiniana.

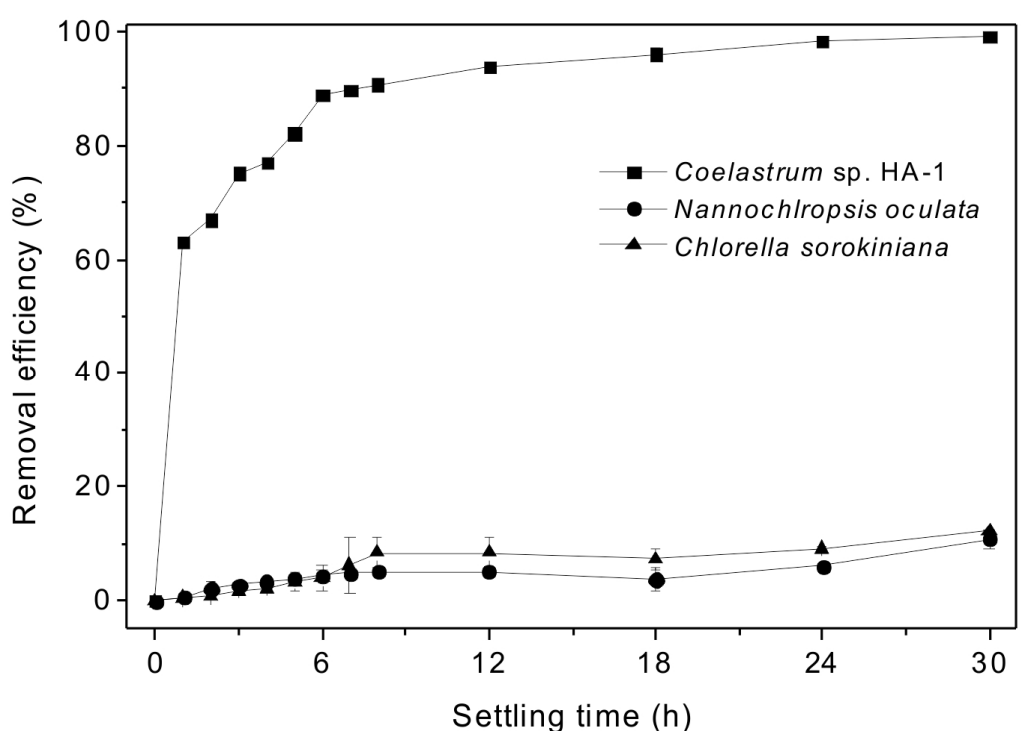




\subsection{Effects of $\mathrm{NaNO}_{3}$ on Growth, Lipid and Astaxanthin Accumulation}

Typical nitrate concentrations in open-ocean surface waters is very low $(0.85-1.7 \mu \mathrm{g} / \mathrm{L})$ [32]. In order to improve biomass, the media can be supplemented with nitrate, which was the best nitrogen source [33]. Coelastrum sp. HA-1 reached stationary phase until day 24 when cultivated at different $\mathrm{NaNO}_{3}$ concentrations. With the initial $\mathrm{NaNO}_{3}$ concentration increasing from 0.075 to $0.9 \mathrm{~g} / \mathrm{L}, \mathrm{DCW}$ increased from 1.45 to $6.48 \mathrm{~g} / \mathrm{L}$ after cultivation for 24 days, and the highest biomass reached $6.48 \mathrm{~g} / \mathrm{L}$ when the initial $\mathrm{NaNO}_{3}$ concentration was $0.9 \mathrm{~g} / \mathrm{L}$ (Figure 5a). Meanwhile, $\mathrm{NaNO}_{3}$ with initial concentrations of $0.075,0.15,0.3,0.6$ and $0.9 \mathrm{~g} / \mathrm{L}$ was completely used at day 4, 4, 4, 6 and 8, respectively (Figure $5 \mathrm{~b}$ ). The results suggested that the higher nitrogen supply conducted to higher biomass accumulation, which is consistent with the results reported by Long, who suggested that nitrogen was the most important element affecting the growth of algae in nutrient deprived media [34].

The influence of nitrogen concentration on the metabolites of Coelastrum sp. HA-1 is shown in Figure 6. The lipid content decreased from $43.3 \%$ to $30.5 \%$ DCW after 24 days when the $\mathrm{NaNO}_{3}$ increased from 0.075 to $0.9 \mathrm{~g} / \mathrm{L}$ (Figure 6a). This pattern is similar to the one reported by Illman who observed that the lipid content of Chlorella vulgaris increased from $18 \%$ to $40 \%$ when the culture medium was changed from "control" to "low-nitrogen" [35]. Hu summarized that the total lipids in microalgae varied from $5 \%$ to $80 \%$ of dry weight, and oleaginous algae had an average oil content of 25.5\% DCW [36]. Our results show a highest lipid yield of $18.0 \mathrm{~g} \mathrm{~m}^{-2}$ day $^{-1}$ (equal to $2.3 \mathrm{~g} / \mathrm{L}$ ) corresponding to a biomass content of $5.83 \mathrm{~g} / \mathrm{L}$ when the $\mathrm{NaNO}_{3}$ initial concentration was $0.6 \mathrm{~g} / \mathrm{L}$ after cultivation for 24 days, which was higher than those of Mychonastes afer HSO-3-1, a potential new source for biodiesel with a highest biomass and lipid yield of $3.29 \mathrm{~g} / \mathrm{L}$ and $1.62 \mathrm{~g} / \mathrm{L}$ after cultivation for 14 days reported by Yuan et al. [18]. The astaxanthin content of HA-1 decreased from 6.36 to $3.32 \mathrm{mg} / \mathrm{g}$ when the $\mathrm{NaNO}_{3}$ initial concentration increased from 0.075 to $0.9 \mathrm{~g} / \mathrm{L}$ (Figure $6 \mathrm{~b}$ ). Nonetheless, the highest astaxanthin yield was up to $168.9 \mathrm{mg} \mathrm{m}^{-2}$ day $^{-1}$ when the $\mathrm{NaNO}_{3}$ was $0.9 \mathrm{~g} / \mathrm{L}$ after cultivation for 24 days. The highest astaxanthin content of HA-1 was obtained under nitrogen-limiting condition and varied in a way similar to Zhekisheva's report that astaxanthin of H. pluvialis sharply increased to $58.5 \mathrm{mg} / \mathrm{L}$ under nitrogen-starvation condition [27].

Figure 5. Growth curves (a) and nitrogen consumption (b) of Coelastrum sp. HA-1 at different initial $\mathrm{NaNO}_{3}$ concentrations.
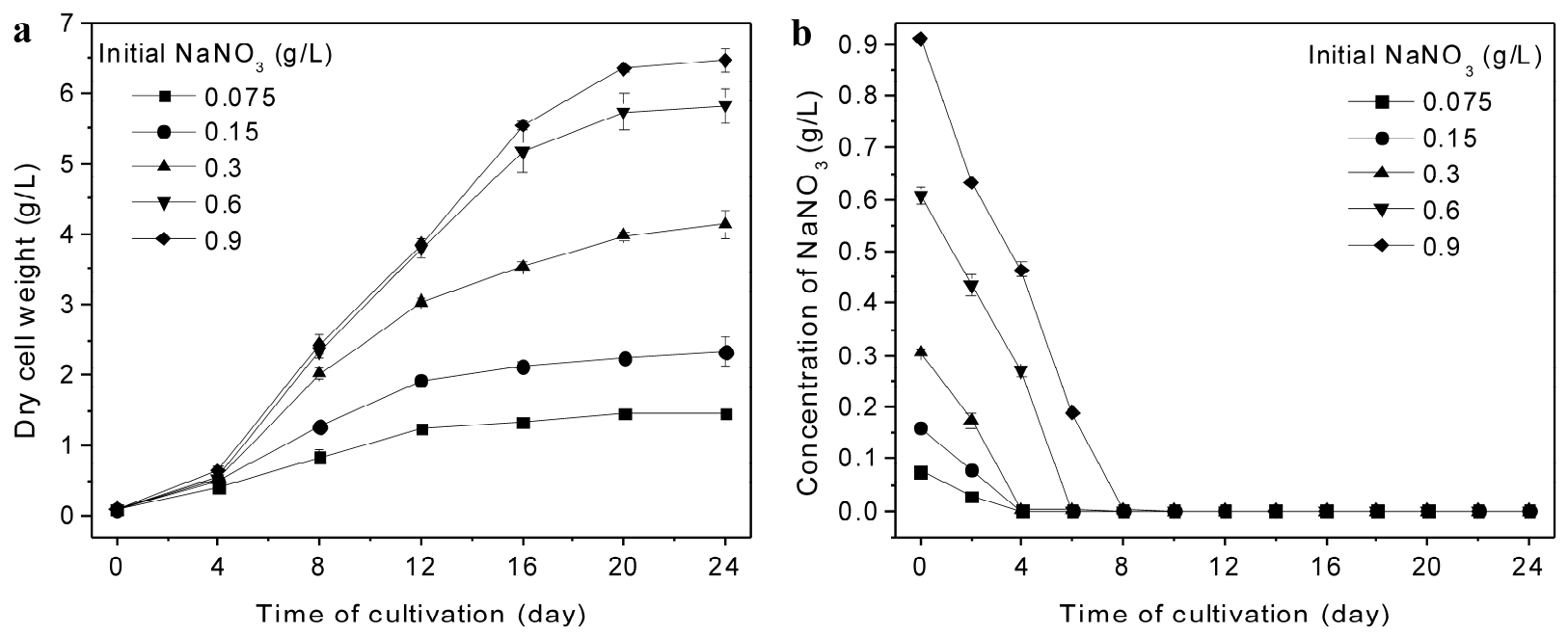
Figure 6. Lipid (a) and astaxanthin (b) accumulation of Coelastrum sp. HA-1 at different initial $\mathrm{NaNO}_{3}$ concentrations after cultivation for 24 days.
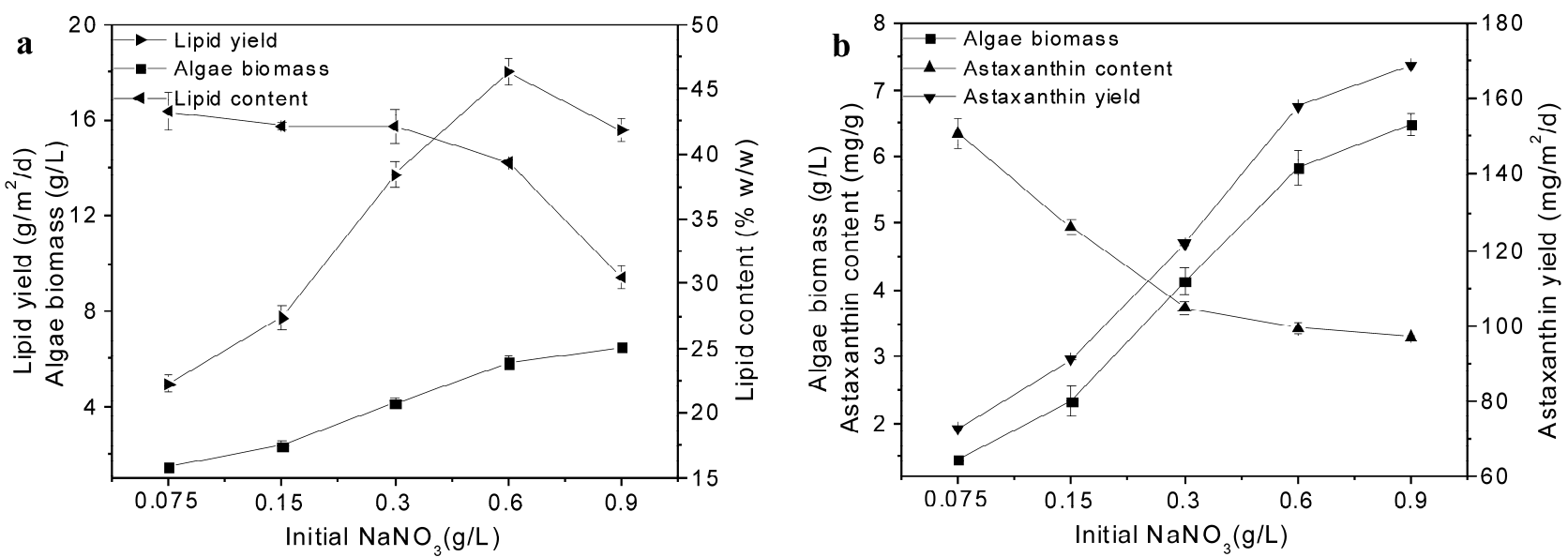

Due to the fact that the highest lipid and astaxanthin yields could not be reached at the same concentration, it is key to choose a better concentration to culture HA-1. Our results show that the initial $\mathrm{NaNO}_{3}$ of $0.6 \mathrm{~g} / \mathrm{L}$ is the optimal concentration to culture this strain. When the initial $\mathrm{NaNO}_{3}$ concentration decreased from 0.9 to $0.6 \mathrm{~g} / \mathrm{L}$, the yield of lipid increased from 15.5 to $18.0 \mathrm{~g} \mathrm{~m}^{-2} \mathrm{day}^{-1}$ by the ratio of $16.1 \%$, and the yield of astaxanthin decreased from 168.9 to $157.8 \mathrm{mg} \mathrm{m}^{-2}$ day $^{-1}$ by the ratio of $7.0 \%$; the ratio of lipid increased was significantly higher than that of astaxanthin decreased. On the other hand, the cost is lower when decreasing the $\mathrm{NaNO}_{3}$ concentration.

The changes in FA composition of Coelastrum sp. HA-1 at different nitrogen concentrations were further investigated. Results show that compositions of FAs also changed at the different $\mathrm{NaNO}_{3}$ concentrations (Table 2). The content of UFA was not significantly changed with increasing initial $\mathrm{NaNO}_{3}$ concentrations, but MUFA decreased from $64.49 \%$ to $62.1 \%$ while PUFA increased from $6.32 \%$ to $8.17 \%$. Octadecenoic acid (C18:n, $n=1-4)$ and myristic acid (C14:0) decreased from $63.39 \%$ and $0.38 \%$ to $60.74 \%$ and $0.24 \%$ with increasing initial $\mathrm{NaNO}_{3}$ concentrations, respectively. The trend was similar to Zhekisheva's report that oleic acid up to $34 \%$ of FAs under nitrogen starvation conditions decreased to $13 \%$ in the control [27]. Hexadecenoic acid (C16:n, $n=1-4)$, octadecanoic acid and octacosanoic acid all increased with increased initial $\mathrm{NaNO}_{3}$ concentrations. None of the changes were remarkable, so FA profiles of strain HA-1 are suitable for biofuel at different initial $\mathrm{NaNO}_{3}$ concentrations as discussed earlier.

Table 2. Effects of initial $\mathrm{NaNO}_{3}$ concentration on fatty acid compositions of Coelastrum sp. HA-1.

\begin{tabular}{|c|c|c|c|c|c|}
\hline \multirow{2}{*}{ Fatty acids } & \multicolumn{5}{|c|}{ Relative content of the total fatty acids $(\%, w / w)$} \\
\hline & $0.075 \mathrm{~g} / \mathrm{L} \mathrm{NaNO}_{3}$ & $0.15 \mathrm{~g} / \mathrm{L} \mathrm{NaNO}_{3}$ & $0.3 \mathrm{~g} / \mathrm{L} \mathrm{NaNO}_{3}$ & $0.6 \mathrm{~g} / \mathrm{L} \mathrm{NaNO}_{3}$ & $0.9 \mathrm{~g} / \mathrm{L} \mathrm{NaNO}_{3}$ \\
\hline C14:0 & 0.38 & 0.35 & 0.25 & 0.23 & 0.24 \\
\hline $\mathrm{C} 16: 0$ & 26.29 & 26.03 & 26.56 & 25.53 & 25.65 \\
\hline C16:1 & 2.32 & 3.11 & 2.67 & 3.05 & 3.23 \\
\hline $\mathrm{C} 16: 2$ & 3.69 & 4.15 & 3.65 & 4.64 & 5.01 \\
\hline $\mathrm{C} 16: 4$ & 0.87 & 0.95 & 0.81 & 0.88 & 0.81 \\
\hline C18:0 & 2.42 & 2.55 & 2.99 & 3.69 & 3.62 \\
\hline
\end{tabular}


Table 2. Cont.

\begin{tabular}{|c|c|c|c|c|c|}
\hline \multirow{2}{*}{ Fatty acids } & \multicolumn{5}{|c|}{ Relative content of the total fatty acids $(\%, w / w)$} \\
\hline & $0.075 \mathrm{~g} / \mathrm{L} \mathrm{NaNO}_{3}$ & $0.15 \mathrm{~g} / \mathrm{L} \mathrm{NaNO}_{3}$ & $0.3 \mathrm{~g} / \mathrm{L} \mathrm{NaNO}_{3}$ & $0.6 \mathrm{~g} / \mathrm{L} \mathrm{NaNO}_{3}$ & $0.9 \mathrm{~g} / \mathrm{L} \mathrm{NaNO}_{3}$ \\
\hline C18:1 & 61.63 & 60.8 & 60.63 & 58.73 & 58.39 \\
\hline $\mathrm{C} 18: 2$ & 1.35 & 1.15 & 1.4 & 1.78 & 1.58 \\
\hline $\mathrm{C} 18: 4$ & 0.41 & 0.26 & 0.44 & 0.77 & 0.77 \\
\hline $\mathrm{C} 20: 1$ & 0.54 & 0.48 & 0.42 & 0.51 & 0.48 \\
\hline $\mathrm{C} 28: 0$ & 0.1 & 0.17 & 0.18 & 0.19 & 0.22 \\
\hline SFA & 29.19 & 29.1 & 29.98 & 29.64 & 29.73 \\
\hline UFA & 70.81 & 70.9 & 70.02 & 70.36 & 70.27 \\
\hline MUFA & 64.49 & 64.39 & 63.72 & 62.29 & 62.1 \\
\hline PUFA & 6.32 & 6.51 & 6.3 & 8.07 & 8.17 \\
\hline
\end{tabular}

\subsection{Economic Analysis of HA-1 for Biofuel}

Based on economic analysis of autotrophic microalgae for fuel production, Davis reported that the cost of lipid production to achieve a $10 \%$ return was determined to be $\$ 8.52 /$ gal for open ponds [37]. Davis suggested that the cost would increase $\$ 1 /$ gal if using freshwater as supply in the sensitivity analysis, therefore it is advantageous to Coelastrum sp. HA-1 which can be cultured in seawater or/and brackish water. Moreover, HA-1 can be harvested by simply setting without flocculant; according to Davis's sensitivity analysis, the cost would decrease $\$ 0.8 /$ gal lipid production. On the other hand, compared with $<\$ 1,000 / \mathrm{t}$ for crude algal oil, astaxanthin commanded a price in the region of $\$ 3$ million/t [6]. Therefore, astaxanthin from HA-1 as a co-product would create an extra gross receipt of $\$ 0.02$ million/t biomass (based on astaxanthin content of $6.36 \mathrm{mg} / \mathrm{g}$ biomass from the above discussed results). This demonstrates that HA-1 is a potential economical feedstock for biofuel production.

\section{Conclusions}

In this study, a naturally occurring marine microalga HA-1 was isolated and named Coelastrum sp. HA-1 based on its morphological and molecular identification. This strain was found to be a potential economical feedstock for biofuel production, due to its unique characteristics: (i) HA-1 could be cultured in seawater; (ii) high lipid yield and suitable FA profiles were also achieved; (iii) astaxanthin as a co-product from HA-1 could create additional revenue; and (iv) gravity sedimentation could be used as the harvesting method. In photoautotrophic cultivation for 24 days, the highest biomass and astaxanthin yield were $50.9 \mathrm{~g} \mathrm{~m}^{-2}$ day $^{-1}$ and $168.9 \mathrm{mg} \mathrm{m}^{-2}$ day ${ }^{-1}$, respectively, when the initial $\mathrm{NaNO}_{3}$ concentration was $0.9 \mathrm{~g} / \mathrm{L}$, and the highest lipid yield $18.0 \mathrm{~g} \mathrm{~m}^{-2}$ day $^{-1}$ was obtained at $0.6 \mathrm{~g} / \mathrm{L} \mathrm{NaNO}_{3}$.

\section{Acknowledgments}

This work was supported partially by the National Program on Key Basic Research Project (2011CB200905 and 2011CB200906) and the National Natural Science Foundation of China (Grant No. 31200093), Science and Technology Support Key Project Plan of Tianjin (12ZCZDSFO2000). We thank Yubin Zheng in Washington State University for improving the English of this manuscript. 


\section{References}

1. Huo, S.; Dong, R.; Wang, Z.; Pang, C.; Yuan, Z.; Zhu, S.; Chen, L. Available resources for algal biofuel development in China. Energies 2011, 4, 1321-1335.

2. Scott, S.A.; Davey, M.P.; Dennis, J.S.; Horst, I.; Howe, C.J.; Lea-Smith, D.J.; Smith, A.G. Biodiesel from algae: Challenges and prospects. Curr. Opin. Biotechnol. 2010, 21, 277-286.

3. Oltra, C. Stakeholder perceptions of biofuels from microalgae. Energy Policy 2011, 39, 1774-1781.

4. Brennan, L.; Owende, P. Biofuels from microalgae-A review of technologies for production, processing, and extractions of biofuels and co-products. Renew. Sustain. Energy Rev. 2010, 14, $557-577$.

5. Mata, T.M.; Martins, A.A.; Caetano, N.S. Microalgae for biodiesel production and other applications: A review. Renew. Sustain. Energy Rev. 2010, 14, 217-232.

6. Williams, P.J.; Laurens, L.M.L. Microalgae as biodiesel \& biomass feedstocks: Review \& analysis of the biochemistry, energetics \& economics. Energy Environ. Sci. 2010, 3, 554-590.

7. Chen, F.; Liu, Z.; Li, D.; Liu, C.; Zheng, P.; Chen, S. Using ammonia for algae harvesting and as nutrient in subsequent cultures. Bioresour. Technol. 2012, 121, 298-303.

8. Mandal, S.; Mallick, N. Microalga Scenedesmus obliquus as a potential source for biodiesel production. Appl. Microbiol. Biotechnol. 2009, 84, 281-291.

9. Thana, P.; Machmudah, S.; Goto, M.; Sasaki, M.; Pavasant, P.; Shotipruk, A. Response surface methodology to supercritical carbon dioxide extraction of astaxanthin from Haematococcus pluvialis. Bioresour. Technol. 2008, 99, 3110-3115.

10. Guillard, R.R.L.; Ryther, J.H. Studies of marine planktonic diatoms: I. Cyclotella nana hustedt, and Detonula confervacea (cleve) gran. Can. J. Microbiol. 1962, 8, 229-239.

11. Bischoff, H.W.; Bold, H.C. Some Soil Algae from Enchanted Rock and Related Algal Species; Phycological Studies Volume 6318; University of Texas: Austin, TX, USA, 1963.

12. Gamliel, H.; Gurfel, D.; Leizerowitz, R.; Polliack, A. Air-drying human leucocytes for scanning electron microscopy using the GTGO procedure. J. Microsc. 1983, 131, 87-95.

13. Morin, N.; Vallaeys, T.; Hendrickx, L.; Natalie, L.; Wilmotte, A. An efficient DNA isolation protocol for filamentous cyanobacteria of the genus Arthrospira. J. Microbiol. Methods 2010, 80, $148-154$.

14. Tamura, K.; Peterson, D.; Peterson, N.; Stecher, G.; Nei, M.; Kumar, S. MEGA5: Molecular evolutionary genetics analysis using maximum likelihood, evolutionary distance, and maximum parsimony methods. Mol. Biol. Evol. 2011, 28, 2731-2739.

15. Saitou, N.; Nei, M. The neighbor-joining method: A new method for reconstructing phylogenetic trees. Mol. Biol. Evol. 1987, 4, 406-425.

16. Felsenstein, J. Confidence limits on phylogenies: An approach using the bootstrap. Evolution 1985, 39, 783-791.

17. Tamura, K.; Nei, M.; Kumar, S. Prospects for inferring very large phylogenies by using the neighbor-joining method. Proc. Natl. Acad. Sci. USA 2004, 101, 11030-11035.

18. Yuan, C.; Liu, J.; Fan, Y.; Ren, X.; Hu, G.; Li, F. Mychonastes afer HSO-3-1 as a potential new source of biodiesel. Biotechnol. Biofuels 2011, 4, 47:1-47:8. 
19. Yang, X.; Liu, P.; Hao, Z.; Shi, J.; Zhang, S. Characterization and identification of freshwater microalgal strains toward biofuel production. Bioresources 2012, 7, 686-695.

20. Couso, I.; Vila, M.; Vigara, J.; Cordero, B.F.; Vargas, M.Á.; Rodríguez, H.; León, R. Synthesis of carotenoids and regulation of the carotenoid biosynthesis pathway in response to high light stress in the unicellular microalga Chlamydomonas reinhardtii. Eur. J. Phycol. 2012, 47, 223-232.

21. Rodríguez, M.C.; Cerezo, A.S. The resistant "biopolymer" in cell walls of Coelastrum sphaericum. Phytochemistry 1996, 43, 731-734.

22. Hegewald, E.; Wolf, M.; Keller, A.; Friedl, T.; Krienitz, L. ITS2 sequence-structure phylogeny in the Scenedesmaceae with special reference to Coelastrum (Chlorophyta, Chlorophyceae), including the new genera Comasiella and Pectinodesmus. Phycologia 2010, 49, 325-335.

23. Gao, Z.; Meng, C.; Zhang, X.; Xu, D.; Miao, X.; Wang, Y.; Yang, L.; Lv, H.; Chen, L.; Ye, N. Induction of salicylic acid (SA) on transcriptional expression of eight carotenoid genes and astaxanthin accumulation in Haematococcus pluvialis. Enzym. Microb. Technol. 2012, 51, 225-230.

24. Collins, A.M.; Jones, H.D.T.; Han, D.; Hu, Q.; Beechem, T.E.; Timlin, J.A. Carotenoid distribution in living cells of Haematococcus pluvialis (Chlorophyceae). PloS One 2011, 6, e24302:1-e24302:7.

25. Del Campo, J.A.; Rodríguez, H.; Moreno, J.; Vargas, M.Á.; Rivas, J.; Guerrero, M.G. Accumulation of astaxanthin and lutein in Chlorella zofingiensis (Chlorophyta). Appl. Microbiol. Biotechnol. 2004, 64, 848-854.

26. Sarada, R.; Tripathi, U.; Ravishankar, G.A. Influence of stress on astaxanthin production in Haematococcus pluvialis grown under different culture conditions. Process Biochem. 2002, 37, 623-627.

27. Zhekisheva, M.; Boussiba, S.; Khozin-Goldberg, I.; Zarka, A.; Cohen, Z. Accumulation of oleic acid in Haematococcus pluvialis (Chlorophyceae) under nitrogen starvation or high light is correlated with that of astaxanthin esters. J. Phycol. 2002, 38, 325-331.

28. Damiani, M.C.; Popovich, C.A.; Constenla, D.; Leonardi, P.I. Lipid analysis in Haematococcus pluvialis to assess its potential use as a biodiesel feedstock. Bioresour. Technol. 2010, 101, 3801-3807.

29. Nascimento, M.D.; Ortiz-Marquez, J.C.F.; Sanchez-Rizza, L.; Echarte, M.M.; Curatti, L. Bioprospecting for fast growing and biomass characterization of oleaginous microalgae from South-Eastern Buenos Aires, Argentina. Bioresour. Technol. 2012, 125, 283-290.

30. Xu, H.; Miao, X.; Wu, Q. High quality biodiesel production from a microalga Chlorella protothecoides by heterotrophic growth in fermenters. J. Biotechnol. 2006, 126, 499-507.

31. Uduman, N.; Qi, Y.; Danquah, M.K.; Forde, G.M.; Hoadley, A. Dewatering of microalgal cultures: A major bottleneck to algae-based fuels. J. Renew. Sustain. Energy 2010, 2, 012701:1-012701:15.

32. Raimbault, P.; Slawyk, G.; Coste, B.; Fry, J. Feasibility of using an automated colorimetric procedure for the determination of seawater nitrate in the 0 to $100 \mathrm{nM}$ range: Examples from field and culture. Mar. Biol. 1990, 104, 347-351.

33. Li, Y.; Horsman, M.; Wang, B.; Wu, N.; Lan, C.Q. Effects of nitrogen sources on cell growth and lipid accumulation of green alga Neochloris oleoabundans. Appl. Microbiol. Biotechnol. 2008, 81, 629-636. 
34. Long, T.; Wu, L.; Meng, G.; Guo, W. Numerical simulation for impacts of hydrodynamic conditions on algae growth in Chongqing Section of Jialing River, China. Ecol. Model. 2011, 222, $112-119$.

35. Illman, A.M.; Scragg, A.H.; Shales, S.W. Increase in Chlorella strains calorific values when grown in low nitrogen medium. Enzym. Microb. Technol. 2000, 27, 631-635.

36. Hu, Q.; Sommerfeld, M.; Jarvis, E.; Ghirardi, M.; Posewitz, M.; Seibert, M.; Darzins, A. Microalgal triacylglycerols as feedstocks for biofuel production: Perspectives and advances. Plant J. 2008, 54, 621-639.

37. Davis, R.; Aden, A.; Pienkos, P.T. Techno-economic analysis of autotrophic microalgae for fuel production. Appl. Energy 2011, 88, 3524-3531.

(C) 2013 by the authors; licensee MDPI, Basel, Switzerland. This article is an open access article distributed under the terms and conditions of the Creative Commons Attribution license (http://creativecommons.org/licenses/by/3.0/). 